\title{
Contraceptive use among lactating women in Ganta-Afeshum District, Eastern Tigray, Northern Ethiopia, 2015: a cross sectional study
}

\author{
Alem Gebremariam* and Hadush Gebremariam
}

\begin{abstract}
Background: Women who are not exclusively breastfeeding are at risk of pregnancy after four to six weeks of childbirth. Postpartum contraceptive use is crucial to prevent unintended pregnancy, and to have spaced births. The study was conducted to determine the magnitude of modern contraceptive utilization and factors associated with it among lactating women in Ganta-Afeshum district.

Methods: A community based cross sectional study was conducted among lactating women with children in the age group of six to twelve months. A total of 605 women were included in the study. The study participants were selected using cluster sampling method. Data were collected using structured interviewer administered Tigrigna version questionnaire. Data were analyzed using SPSS version 21. Multivariable logistic regression was used to control the effect of confounders.

Results: The magnitude of institutional delivery was $96.5 \%$. The mode of delivery of the participants was spontaneous, instrumental and caesarean section, 95.5\%, 2.0\%, and 2.5\%, respectively. The magnitude of modern contraceptive (MC) utilization was $68.1 \%$ (95\% Cl: 64.4-71.8). The contraceptive method mix was dominated by Depo-Provera (58.8\%) followed by implants (31.8\%). Almost all the study participants had at least one antenatal care (ANC) visit (99.7\%) during the pregnancy of their index child. Participants who had radio and those who delivered their recent child by assisted delivery had higher odds of modern contraceptive use.

Conclusions: The magnitude of contraceptive utilization among lactating mothers in the study area was higher than the national survey reports. However, significant numbers of women are not using contraceptives in their postpartum period, making them at risk of pregnancy. Mode of delivery of the women and having radio at home were significantly associated with the women's contraceptive utilization. Family planning information dissemination using radio in rural settings should be encouraged to increase the uptake of contraceptives in the lactating women.
\end{abstract}

Keywords: Contraceptive use, Postpartum, Mode of delivery, Adigrat, Tigray

\footnotetext{
* Correspondence: alemg25@gmail.com

Department of Public Health, College of Medicine and Health Science,

Adigrat University, Adigrat, Ethiopia
} 


\section{Background}

Spaced birth is crucial both for the mother and the child's health [1-3]. Birth spacing at least by two years decrease the rate of infant mortality by $50 \%[2,4]$. Lactating women are at risk for unwanted or unplanned pregnancy immediately after birth. Moreover, more than $50 \%(57.6 \%)$ of the women have short birth interval [5]. Therefore, contraceptive use as early as possible after child birth is important $[1,6]$.

The rate of contraceptive utilization is increasing from time to time [7, 8]. Similarly, in Ethiopia, the rate of contraceptive utilization has been increasing over the last decades. Over the last sixteen years, the rate of contraceptive utilization has increased from $8 \%$ to $36 \%$ [9]. The prevalence of current modern family planning utilization among all women in Oromia region Arsi zone [10] and Tigray region Adigrat town [11] was 65\% and $51.3 \%$, respectively. Contraceptive use is determined by knowledge and educational level of the women [12-14], age of the participants [15], quality of antenatal care [16], male involvement [17] and decision making power of the women [18]. Many studies have been conducted to assess the contraceptive utilization status of women generally $[18,19]$, with only one study targeted to lactating women [15]. So far, few studies have documented the magnitude of contraceptive utilization and factors associated with it among women who were within six to twelve months of their index delivery. Therefore, this study was conducted to document the magnitude of postpartum contraceptive utilization and factors associated with it. This specific study targeted on the lactating women with index child aged 6 months to one year will help programmers and policy makers design specific intervention targeted to these specific segments of women. Besides, it could serve as a baseline data for further future studies.

\section{Methods}

\section{Study area and design}

The study was conducted in Ganta-Afeshum district, Eastern zone of Tigray which is located around $903 \mathrm{~km}$ North of Ethiopia's capital city, Addis Ababa. It is one of the rural districts of Eastern zone of Tigray. A community based cross sectional study was conducted among lactating women who have infant aged six to twelve months in 2015.

\section{Sample size and sampling procedure}

A total of 605 lactating women with an infant aged six to twelve months age were included in the study. Sample size was computed using single population proportion formula considering $51.3 \%$ proportion of modern contraceptive use [11], 95\% confidence level, 5\% margin of error and 1.5 design effects. Considering $5 \%$ of nonresponse rate, the final sample size was 605 .

Out of the 20 kebeles (the smallest administrative unit) in the district, twelve kebeles were selected randomly. Considering the selected kebeles as a cluster, all the eligible women found in the selected kebeles were included in the study. The health extension workers were responsible for identifying households with children between the ages of 6-12 months. We abstracted the lists of women with eligible children from the log book of health extension workers. Those lactating women with an infant aged six to twelve and lived at least six months in the selected kebeles were included in the interview. Eligible mothers who were severely ill or unable to respond for the questionnaire were excluded from the study.

\section{Data collection procedure}

A structured pre-tested interviewer administered questionnaire was used. As much as possible, attempts were made to make questions suitable to the local setting. It was first prepared in English language, and later translated to Tigrigna language. Back translation to English was done to compare the consistency, and amendments were made accordingly.

Ten data collectors were recruited. Besides, four diploma holder nurses were recruited to supervise the data collection process. Both the data collectors and supervisors were trained for two days on the objectives of the study, study instruments and data collection procedure. The questionnaire was pre-tested on $5 \%$ sample in a similar population to the selected kebeles of the district. Revision of the questionnaire was made after the pretest. Supervisors were responsible to supervise, assist interviewers and collect filled questionnaires every day and check for consistencies and completeness of filled questionnaires. Questionnaires with problems were sent back to interviewers for re-interview. The investigators were responsible for coordination and supervision of the overall data collection process.

\section{Data analysis}

The collected data were entered to Epi Info then exported to window based Statistical Package for Social Sciences (SPSS) version 21.0. Data were cleaned for inconsistencies and missing values and amendment was considered as needed. Simple frequencies were run to see the overall distribution of the study subject with the variables under study. Bivariate analysis was used to determine the association between different factors and the outcome variable.

Multivariable logistic regression was used to identify the relative importance of each independent variable to the outcome variable by controlling for the effects of other variables. Variables with $p$-value of 0.2 or less on 
bivariate analysis were included in the multivariable analysis. Multi-collinearity was checked using the Variance Inflation Factor (VIF), and those with VIF greater than 10 were excluded from the model. Participants' age, their index child's age, family size, and total number of births were treated as continuous variable. Family size was correlated with total number of births, and excluded from the multivariable model. The association between modern contraceptive use and independent variables was determined using Odds Ratio (OR) with 95\% Confidence Interval (CI). The level of significance was taken at $\alpha=0.05$.

\section{Ethical statement}

Prior to the data collection, ethical clearance was obtained from Adigrat University ethical clearance committee. Permission letter was written from Tigray Regional Health Bureau to the study district, Ganta-Afeshum. Besides, written cooperation letter was obtained from GantaAfeshum district health office to each of the selected kebeles. Interviewers obtained oral informed consent of the respondents prior to the interview. Participation in the study was completely voluntary and refusal to respond to some of the questions or interruption from the study was possible. All the information obtained from the respondents remained confidential and anonymous. Finally, the dissemination of the finding does not refer specific respondents but the general source population.

\section{Results}

\section{Socio-demographic characteristics of the participants}

A total of 599 women responded fully to the questionnaire making the response rate $99.5 \%$. The mean age of the participants was 30.8 years $(\mathrm{SD}=6.29)$. The median family sizes of the participants were 5 with a minimum of 2 and maximum of 12 . Almost all (99.8\%) of the participants were Tigrie by Ethnicity. Sixty-one percent of the participants were farmers. Forty-one percent of the participants were illiterate (Table 1). Seventy percent and $15 \%(15.3 \%)$ of the participants have radio and television in their home, respectively.

\section{Participants' maternal health service utilization}

The median number of births given by the participants was 3 with the minimum of one and maximum of ten births. The magnitude of institutional delivery was $96.5 \%$. The mode of delivery of the participants was spontaneous, instrumental and caesarean section, 95.5\%, $2.0 \%$, and $2.5 \%$, respectively. Sixteen $(2.7 \%)$ of the participants were assisted by their relatives during the birth of their index child. The magnitude of Modern Contraceptive (MC) utilization was $68.1 \%$ with $95 \%$ CI of $64.4 \%$ to $71.8 \%$. The contraceptive method mix was dominated by Depo-Provera (58.8\%) followed by implants (31.8\%), and pills $(4.9 \%)$ (Table 2$)$.
Table 1 Socio-demographic characteristic of participants in Gnata-Afeshum district, Tigray, $2015(n=599)$

\begin{tabular}{|c|c|c|}
\hline Variables & Frequency (n) & Percent (\%) \\
\hline \multicolumn{3}{|l|}{ Marital status of mother } \\
\hline Married & 572 & 95.5 \\
\hline Ever Married & 27 & 4.5 \\
\hline \multicolumn{3}{|l|}{ Religion } \\
\hline Orthodox & 585 & 97.7 \\
\hline Muslim & 14 & 2.3 \\
\hline \multicolumn{3}{|c|}{ Participants' level of education } \\
\hline Illiterate & 246 & 41.1 \\
\hline Elementary (1-4) & 99 & 16.5 \\
\hline Grade $5-8$ & 127 & 21.2 \\
\hline Grade 9 and above & 127 & 21.2 \\
\hline \multicolumn{3}{|c|}{ Partners' level of education } \\
\hline Illiterate & 151 & 25.2 \\
\hline Elementary (1-4) & 103 & 17.2 \\
\hline Grade 5-8 & 164 & 27.4 \\
\hline Grade 9 and above & 181 & 30.2 \\
\hline \multicolumn{3}{|l|}{ Participant's occupation } \\
\hline Farmer & 240 & 40.0 \\
\hline Housewife & 313 & 52.3 \\
\hline Employed $^{a}$ & 46 & 7.7 \\
\hline
\end{tabular}

aRefers to those who were merchant, daily laborer, and government and privet employed

Almost all the study participants had at least one Antenatal Care (ANC) visit (99.7\%) during the pregnancy of their index child. Three fourths of the participants had made four or more ANC visits (Table 2). During their ANC visit, participants remembered as they received advice on place of delivery (81.6\%), breastfeeding (56.6\%), child immunization (39.4\%), mother's tetanus toxoid vaccination (49.9\%) and family planning utilization after birth (37.6\%) by their care givers.

\section{Factors associated with modern contraceptive use}

On bivariate analysis, sex of their index child, marital status, family size, partners' education status, having radio, number of births and mode of delivery were found significantly associated with modern contraceptive use (Table 3). After inclusion of the variables with $p$-value of less than or equal to 0.2 in to the multivariable logistic regression model, having a radio and mode of delivery were found statistically significantly associated with modern contraceptive use (Table 4).

Women who had no radio in their home had $48 \%$ lower odds of modern contraceptive use compared to those who had radio in their home (AOR $=0.52$; 95\% CI: $0.35,0.77)$. Similarly, mothers whose recent mode of delivery was spontaneous vaginal delivery had $75 \%$ lower 
Table 2 Reproductive history of study participants' of GantaAfeshum district, Tigray, $2015(n=599)$

\begin{tabular}{|c|c|c|}
\hline Variables & Frequency (n) & Percent (\%) \\
\hline \multicolumn{3}{|l|}{ History of abortion } \\
\hline Yes & 79 & 13.2 \\
\hline No & 520 & 86.8 \\
\hline \multicolumn{3}{|l|}{ History of still birth } \\
\hline Yes & 33 & 5.5 \\
\hline No & 566 & 94.5 \\
\hline \multicolumn{3}{|c|}{ Current modern contraceptive use status } \\
\hline Yes & 408 & 68.1 \\
\hline No & 191 & 31.9 \\
\hline \multicolumn{3}{|l|}{ Type of MC used } \\
\hline Depo-Provera & 240 & 58.8 \\
\hline Implants & 130 & 31.8 \\
\hline Pills & 20 & 4.9 \\
\hline Intra uterine contraceptive device & 14 & 3.4 \\
\hline Female sterilization & 4 & 0.1 \\
\hline \multicolumn{3}{|l|}{ Number of ANC visit } \\
\hline 1 & 4 & $0.7 \%$ \\
\hline 2 & 19 & $3.2 \%$ \\
\hline 3 & 132 & $22.1 \%$ \\
\hline 4 & 380 & $63.7 \%$ \\
\hline$>=5$ & 62 & $10.3 \%$ \\
\hline \multicolumn{3}{|l|}{ Birth assisted by } \\
\hline Health provider & 576 & 96.2 \\
\hline Health extension worker & 4 & 0.7 \\
\hline Traditional birth attendant & 3 & 0.5 \\
\hline Family relatives & 16 & 2.7 \\
\hline \multicolumn{3}{|l|}{ Mode of delivery } \\
\hline Spontaneous vaginal delivery & 572 & 95.5 \\
\hline Assisted delivery & 12 & 2.0 \\
\hline Cesarean delivery & 15 & 2.5 \\
\hline
\end{tabular}

$M C$ modern contraceptives, ANC Antenatal care

odds of modern contraceptive use compared to those whose mode of delivery was assisted vaginal delivery and caesarean delivery $(\mathrm{AOR}=0.25 ; 95 \% \mathrm{CI}: 0.07,0.86$ ). Though it was marginally significant $(\mathrm{AOR}=1.46$; $95 \% \mathrm{CI}$ : $0.99,2.15)$, participants who had received advice on family planning during their antenatal care had higher odds of contraceptive use during their postpartum period (Table 4).

\section{Discussion}

This community based cross-sectional study was attempted to assess the magnitude of modern contraceptive utilization among lactating mothers in Gant-Afeshum district. The risk of pregnancy increases when a woman shifted from the period of exclusive breastfeeding to the period of nearly fully breastfeeding. Therefore, using contraceptives is a guarantee to prevent unwanted pregnancy [1]. The magnitude of modern contraceptive utilization rate among lactating women was $68.1 \%$ (95\%CI: $64.4 \%, 71.8 \%$ ). This is higher than the recent national demographic health survey report of modern contraceptive utilization rate [9], and study conducted in Gondar, Northwest Ethiopia [15]. The difference could be explained by the difference in the study subjects where our study is targeted to women who were with index child aged 6 months to one year. Whereas the study in Gondar was inclusive of all women who give birth within one year of birth which included women in the exclusive breastfeeding. Besides, previous study conducted in the neighboring district reported 51.3\% utilization rate among all women [11]. Moreover, this finding is comparable with the findings documented in Arsi Zone [10], and Dawro zone, Southern Ethiopia [18] which was $65 \%$, and $72.8 \%$, respectively. However, it is lower than the finding in Malawi where $75 \%$ of the lactating women were utilizing contraceptives [20]. Similar to other studies [12, 21, 22], the dominant method used was Depo-Provera. This is explained by the simplicity of the procedure to use and to keep secret of their partner [14].

Having radio, and mode of delivery were associated with postpartum contraceptive utilization. Those who had no radio had $48 \%$ lower odds of contraceptive utilization. The study area is a rural district where electricity access is poor and it is difficult to have television. But they can use radio and help them to get family planning related information disseminated using the radio. This is not uncommon in other studies where health providers and mass medias take the highest share of family planning information [12, 23-25]. Similarly, in Uganda, exposure to media $(\mathrm{OR}=1.30 ; 95 \% \mathrm{CI}=1.05-1.61)$ was significantly associated with postpartum contraceptive utilization [26].

During the antenatal care, postpartum family planning is one of the counseling given to the women about their pregnancy care. Though it is marginally significant, women who had received family planning advice during their pregnancy care had $46 \%$ higher odds of contraceptive use. This was also documented in Gondar [15], Kenya and Zambia [16] where the intensity of antenatal care was associated with postpartum contraceptive use.

Women whose mode of delivery was spontaneous had a $73 \%$ lower risk of contraceptive utilization. This could, be explained by the difference in the health professionals who attended the labor. Moreover, women who delivered by cesarean section or assisted delivery could be at higher fear of next pregnancy and want to avoid pregnancy. Mengesha and his colleagues also documented higher odds of contraceptive use among women who delivered with the assistance of skilled attendant $(\mathrm{OR}=1.88)$ compared to those who did not receive skilled care during delivery [22]. Similarly, a study in Uganda, found that deliveries attended by 
Table 3 Bivariate analysis of socio-demographic and reproductive characteristics of the participants with modern contraceptive utilization

\begin{tabular}{|c|c|c|c|c|}
\hline \multirow[t]{2}{*}{ Variables } & \multicolumn{2}{|l|}{ MC Use } & \multirow[t]{2}{*}{ Crude OR(95\% Cl) } & \multirow[t]{2}{*}{$P$-value } \\
\hline & Yes, n(\%) & No, n(\%) & & \\
\hline \multicolumn{5}{|l|}{ Sex of the child } \\
\hline Male & $246(71.5 \%)$ & $98(28.5 \%)$ & Ref. & \\
\hline Female & $162(63.5 \%)$ & $93(36.5 \%)$ & $0.69(0.49,0.98)$ & 0.039 \\
\hline Index child's age & $408(68.1 \%)$ & 191(31.9\%) & $0.95(0.86,1.04)$ & 0.263 \\
\hline Age of the participants & $408(68.1 \%)$ & 191(31.9\%) & $0.98(0.95,1.00)$ & 0.154 \\
\hline \multicolumn{5}{|l|}{ Mother's marital status } \\
\hline Married & $394(68.9 \%)$ & 178(31.1\%) & $2.05(0.95,4.46)$ & 0.069 \\
\hline Ever Married & 14(51.9\%) & 13(48.1\%) & Ref. & \\
\hline Family size & $408(68.1 \%)$ & 191(31.9\%) & $0.91(0.83,0.99)$ & 0.030 \\
\hline \multicolumn{5}{|c|}{ Participants' level of education } \\
\hline Illiterate & $165(67.1 \%)$ & $81(32.9 \%)$ & Ref. & \\
\hline Elementary (1-4) & $63(63.6 \%)$ & $36(28.3 \%)$ & $0.85(0.52,1.402)$ & 0.54 \\
\hline Grade $5-8$ & $91(71.7 \%)$ & $36(28.3 \%)$ & $1.24(0.77,1.98)$ & 0.367 \\
\hline Grade 9 and above & $89(70.1 \%)$ & $38(29.9 \%)$ & $1.15(0.72,1.83)$ & 0.555 \\
\hline \multicolumn{5}{|c|}{ Partners' level of education } \\
\hline Illiterate & 106(70.2\%) & $45(29.8 \%)$ & Ref. & \\
\hline Elementary (1-4) & $60(58.3 \%)$ & $43(41.7 \%)$ & $0.59(0.35,1.00)$ & 0.050 \\
\hline Grade 5-8 & $101(61.6 \%)$ & 63(38.4\%) & $0.68(0.42,1.08)$ & 0.108 \\
\hline Grade 9 and above & $141(77.9 \%)$ & $40(22.1 \%)$ & $1.49(0.91,2.45)$ & 0.110 \\
\hline \multicolumn{5}{|l|}{ Mother's occupation } \\
\hline Farmer & $157(65.4 \%)$ & $83(34.6 \%)$ & Ref. & \\
\hline Housewife & $217(69.3 \%)$ & $96(30.7 \%)$ & $1.19(0.83,1.71)$ & 0.330 \\
\hline Employed & $34(73.9 \%)$ & $12(26.1 \%)$ & $1.49(0.73,3.04)$ & 0.265 \\
\hline \multicolumn{5}{|l|}{ Have radio } \\
\hline Yes & $304(72.4 \%)$ & $116(27.6 \%)$ & Ref. & \\
\hline No & $104(58.1 \%)$ & 75(41.9\%) & $0.52(0.36,0.76)$ & 0.001 \\
\hline \multicolumn{5}{|l|}{ Have TV } \\
\hline Yes & $56(62.2 \%)$ & $34(37.8 \%)$ & Ref. & \\
\hline No & $352(69.2 \%)$ & 157(30.8\%) & $1.36(0.85,2.17)$ & 0.194 \\
\hline Total number of births & $408(68.1 \%)$ & 191(31.9\%) & $0.89(0.82,0.97)$ & 0.009 \\
\hline \multicolumn{5}{|l|}{ History of abortion } \\
\hline Yes & $49(62.0 \%)$ & $30(38.0 \%)$ & Ref. & \\
\hline No & $359(69.0 \%)$ & $161(31.0 \%)$ & $1.36(0.83,2.23)$ & 0.214 \\
\hline \multicolumn{5}{|l|}{ History of still birth } \\
\hline Yes & $20(60.6 \%)$ & 13(39.4\%) & Ref. & \\
\hline No & $388(68.6 \%)$ & 178(31.4\%) & $1.41(0.68,2.91)$ & 0.343 \\
\hline Number of ANC visit & $408(68.1 \%)$ & 191(31.9\%) & $1.06(0.83,1.35)$ & 0.603 \\
\hline \multicolumn{5}{|c|}{ Advice on family planning during ANC } \\
\hline Yes & $245(65.9 \%)$ & $127(34.1 \%)$ & $1.36(0.95,1.96)$ & 0.094 \\
\hline No & $163(72.4 \%)$ & $62(27.6 \%)$ & Ref. & \\
\hline
\end{tabular}


Table 3 Bivariate analysis of socio-demographic and reproductive characteristics of the participants with modern contraceptive utilization (Continued)

\begin{tabular}{|c|c|c|c|c|}
\hline \multirow[t]{2}{*}{ Variables } & \multicolumn{2}{|l|}{ MC Use } & \multirow[t]{2}{*}{ Crude OR(95\% Cl) } & \multirow[t]{2}{*}{$P$-valu } \\
\hline & Yes, n(\%) & No, n(\%) & & \\
\hline \multicolumn{5}{|l|}{ Place of delivery } \\
\hline Home & $16(76.2 \%)$ & $5(23.8 \%)$ & Ref. & \\
\hline Health institution & $392(67.8 \%)$ & $186(32.2 \%)$ & $0.65(0.23,1.83))$ & 0.422 \\
\hline \multicolumn{5}{|l|}{ Mode of delivery } \\
\hline Spontaneous vaginal delivery & $384(67.1 \%)$ & 188(32.9\%) & $0.25(0.07,0.86)$ & 0.027 \\
\hline Non-spontaneous delivery & $24(88.9 \%)$ & $3(11.1 \%)$ & Ref. & \\
\hline
\end{tabular}

skilled birth attendance $(\mathrm{OR}=1.39 ; 95 \% \mathrm{CI}=1.12-1.17)$ and $1-2$ days timing of post-delivery care $(\mathrm{OR}=1.68$; $95 \%$ $\mathrm{CI}=1.14-2.47)$ were associated with postpartum contraceptive utilization [26].

Postpartum contraceptive utilization was associated with primary or higher education, age of woman, and number of surviving children [26]. However, this study did not find statistical significant difference across these characteristics. Similar to our finding, partner's level of education was not significantly associated with postpartum contraceptive use in Gondar [22]. Though it is not statistically significant, the multivariable model result suggested an increase in odds of contraceptive use as the level of partner's education increased. This insignificance could be explained by the sample size we used which may not be sufficient

Table 4 Multivariable analysis of selected variables of the participants with modern contraceptive utilization

\begin{tabular}{|c|c|c|c|}
\hline Variables & COR(95\% Cl) & AOR $(95 \% \mathrm{Cl})$ & P-Value \\
\hline \multicolumn{4}{|l|}{ Sex of the index child } \\
\hline Male & Ref. & Ref. & \\
\hline Female & $0.69(0.49,0.98)$ & $0.74(0.51,1.07)$ & 0.109 \\
\hline Age of the participants & $0.98(0.95,1.00)$ & $1.02(0.97,1.06)$ & 0.433 \\
\hline \multicolumn{4}{|l|}{ Participant's marital status } \\
\hline Married & $2.05(0.95,4.46)$ & $1.99(0.88,4.51)$ & 0.097 \\
\hline Ever married & Ref. & Ref. & \\
\hline \multicolumn{4}{|l|}{ Partner's level of education } \\
\hline Illiterate & Ref. & Ref. & \\
\hline Elementary (1-4) & $0.59(0.35,1.00)$ & $0.58(0.33,1.00)$ & 0.053 \\
\hline Grade 5-8 & $0.68(0.42,1.08)$ & $0.63(0.37,1.07)$ & 0.087 \\
\hline Grade 9 and above & $1.49(0.91,2.45)$ & $1.28(0.70,2.31)$ & 0.415 \\
\hline \multicolumn{4}{|l|}{ Have radio } \\
\hline Yes & Ref. & Ref. & \\
\hline No & $0.52(0.36,0.76)$ & $0.52(0.35,0.77)$ & 0.001 \\
\hline \multicolumn{4}{|l|}{ Have Television } \\
\hline Yes & Ref. & Ref. & \\
\hline No & $1.36(0.85,2.17)$ & $1.55(0.93,2.57)$ & 0.086 \\
\hline Total number of births & $1.11(1.03,1.21)$ & $0.89(0.78,1.02)$ & 0.096 \\
\hline \multicolumn{4}{|c|}{ Advice on family planning during ANC } \\
\hline Yes & $1.36(0.95,1.96)$ & $1.46(0.99,2.15)$ & 0.051 \\
\hline No & Ref. & Ref. & \\
\hline \multicolumn{4}{|l|}{ Mode of delivery } \\
\hline Spontaneous vaginal delivery & $0.25(0.07,0.86)$ & $0.27(0.08,0.94)$ & 0.039 \\
\hline Non-spontaneous delivery & Ref. & Ref. & \\
\hline
\end{tabular}


enough to detect the difference of contraceptive use across the levels of partner's education.

The cross-sectional nature of the data has causality challenges. It is difficult to ascertain the association between postpartum contraceptive utilization and the predictor variables since they were measured at one point in time. The study did not address all health system related factors and history of prior use of contraceptives in previous pregnancies that could affect the current postpartum family planning utilization. Though training on the objectives and procedures of the data collection was given to the data collectors, the issue of interviewer and social desirability bias is inevitable.

\section{Conclusions}

Compared to the national and pocket study findings, the magnitude of contraceptive utilization among lactating mothers in the study area was higher than the national survey findings. However, significant numbers of women were not using contraceptives in their postpartum period, making themselves at risk of pregnancy. Family planning advice during antenatal care, mode of delivery of the women and having a radio were significantly associated with the women's postpartum contraceptive utilization. Family planning information dissemination using radio in the rural settings should be encouraged to increase the uptake of contraceptives in the lactating women. Strengthening of the family planning advice provision to the women during their antenatal care should be emphasized. Detail prospective studies should be conducted to investigate the effect of antenatal care service utilization on postpartum contraceptive utilization.

\section{Abbreviations}

ANC: Antenatal Care; AOR: Adjusted Odds Ratio; Cl: Confidence Interval; COR: Crude Oddis Ratio; MC: Modern Contraceptive; OR: Odds Ratio

\section{Acknowledgements}

We would like to extend our gratitude to Adigrat University for funding this research project. We would like to extend our heartfelt thanks to Tigray Regional Health Bureau for allowing us to conduct this study in Ganta-Afeshum District. We also would like to acknowledge Ganta-Afeshum District health office for their cooperation and for giving all the necessary information. Our appreciation and thanks are also forwarded to all supervisors and data collectors of this study, as well as the study participants for their cooperation and providing us relevant information. Last but not least, I would like to thank Mr. Dean Withroder for his support on editing the language of the manuscript.

\section{Funding}

Adigrat University provided the financial support. The funding organization has no role in design of the study, data collection, analysis, and interpretation of data and in writing the manuscript.

\section{Availability of data and materials}

The datasets generated during and/or analyzed during the current study are available from the corresponding author on reasonable request.

\section{Authors' contributions}

AG carried out the conception and designing the study, performed statistical analysis and wrote the manuscript. HG carried out the conception and designing the study, performed statistical analysis and wrote the manuscript. Both authors read and approved the final manuscript.

Ethics approval and consent to participate

Ethical approval was obtained from Adigrat University ethical clearance committee with the registration number of $\mathrm{AGU} / \mathrm{CMHS} / 033 / 07$, and oral informed consent was taken from the study participants.

\section{Consent for publication}

Not applicable

\section{Competing interests}

The authors declare that they have no competing interests.

\section{Publisher's Note}

Springer Nature remains neutral with regard to jurisdictional claims in published maps and institutional affiliations.

Received: 4 April 2017 Accepted: 5 December 2017

Published online: 16 December 2017

\section{References}

1. World Health Organization. Family planing Global Hand Book for providers [Hand of family planing ]. Geneva, Switzerland World Health Organizetion. 2007. p. 289

2. Fotso JC, Cleland J, Mberu B, Mutua M, Elungata P. Birth spacing and child mortality: an analysis of prospective data from the Nairobi urban health and demographic surveillance system. J Biosoc Sci. 2013;45(6):779-98. PubMed PMID: 22958417. Pubmed Central PMCID: PMC3785173. Epub 2012/09/11. eng

3. Conde-Agudelo A, Rosas-Bermudez A, Castano F, Norton MH. Effects of birth spacing on maternal, perinatal, infant, and child health: a systematic review of causal mechanisms. Stud Fam Plan. 2012;43(2):93-114. PubMed PMID: 23175949. Epub 2012/11/28. eng

4. Dadi AF. A systematic review and meta-analysis of the effect of short birth interval on infant mortality in Ethiopia. PloS one. 2015:10(5):e0126759.

5. Yohannes S, Wondafrash M, Abera M, Girma E. Duration and determinants of birth interval among women of child bearing age in Southern Ethiopia. BMC Pregnancy Childbirth. 2011;11:38. PubMed PMID: 21599927. Pubmed Central PMCID: PMC3112064. Epub 2011/05/24. eng.

6. Saha UR, van Soest A. Contraceptive use, birth spacing, and child survival in Matlab, Bangladesh. Stud Fam Plan. 2013:44(1):45-66. PubMed PMID: 23512873. Epub 2013/03/21. eng

7. Hotchkiss DR, Godha D, Do M. Effect of an expansion in private sector provision of contraceptive supplies on horizontal inequity in modern contraceptive use: evidence from Africa and Asia. Int J Equity Health 2011 Aug 19:10:33. PubMed PMID: 21854584. Pubmed Central PMCID: PMC3171310. Epub 2011/08/23. eng.

8. Madsen EL, Kuang B, Ross J. Tracking changes in states of contraceptive use over time in sub-Saharan Africa through cohort and period analyses. J Biosoc Sci. 2015:47(3):329-44. PubMed PMID: 24674653. Epub 2014/03/29. eng

9. Central Statistical Agency (CSA) [Ethiopia] and ICF. Ethiopia demographic and health survey 2016: key indicators report. Addis Ababa, Ethiopia, and Rockville, Maryland, USA: CSA and ICF; 2016.

10. Tafa M, Haidar J, Fekadu H. Modern family planning use and its relationship with the nutritional status of women of child bearing age at Tena District, Arsi zone Oromia Regional State, Ethiopia 2013: a community based case control study. Gynacol Obstetric. 2015;5(3) https://doi.org/10.4172/2161-0932.1000282.

11. Gebremariam A, Addissie A. Intention to use long acting and permanent contraceptive methods and factors affecting it among married women in Adigrat town, Tigray, Northern Ethiopia. Reproductive health. 2014;11(1):24. PubMed PMID: 24628764. Pubmed Central PMCID: PMC4007570. Epub 2014/03/19. eng

12. Alemayehu M, Lemma H, Abrha K, Adama Y, Fisseha G, Yebyo H, et al. Family planning use and associated factors among pastoralist community of afar region, Eastern Ethiopia. BMC Womens Health. 2016;16(39):1-9.

13. Amentie M, Abera M, Abdulahi M. Utilization of family planning services and influencing factors. Sci J Clin Med. 2015;4(3):52-9.

14. Gebremariam A, Addissie A. Knowledge and perception on long acting and permanent contraceptive methods in adigrat town, tigray, northern ethiopia: a qualitative study. Hindawi; International journal of family medicine. 2014;2014:878639. 
15. Abera Y, Mengesha ZB, Tessema GA. Postpartum contraceptive use in Gondar town, Northwest Ethiopia: a community based cross-sectional study. BMC Womens Health. 2015;15:19. PubMed PMID: 25783651. Pubmed Central PMCID: PMC4344775. Epub 2015/03/19. eng

16. Do M, Hotchkiss D. Relationships between antenatal and postnatal care and post-partum modern contraceptive use: evidence from population surveys in Kenya and Zambia. BMC Health Serv Res. 2013;13:6. PubMed PMID: 23289547. Pubmed Central PMCID: PMC3545900. Epub 2013/01/08. eng

17. Tilahun T, Coene G, Temmerman M, Degomme O. Couple based family planning education: changes in male involvement and contraceptive use among married couples in Jimma zone, Ethiopia. BMC Public Health. 2015, 15:682. PubMed PMID: 26194476. Pubmed Central PMCID: PMC4509724. Epub 2015/07/22. eng

18. Bogale B, Wondafrash M, Tilahun T, Girma E. Married women's decision making power on modern contraceptive use in urban and rural Southern Ethiopia. BMC Public Health. 2011;11:342. PubMed PMID: 21595897. Pubmed Central PMCID: PMC3114727. Epub 2011/05/21. eng

19. Eshete A, Adissu Y. Women's joint decision on contraceptive use in Gedeo zone, Southern Ethiopia: a community based comparative cross-sectional study. Int J Fam Med. 2017;2017:9389072. PubMed PMID: 28367329. Pubmed Central PMCID: PMC5359446. Epub 2017/04/04. eng

20. Bwazi C, Maluwa A, Chimwaza A, Pindani M. Utilization of Postpartum Family Planning Services between Six and Twelve Months of Delivery at Ntchisi District Hospital, Malawi.Health. 2014;6:1724-1737. http://dx.doi.org/ 10.4236/health.2014.614205.

21. Megabiaw B. Awareness and utilization of modern contraceptives among street women in North-West Ethiopia. BMC women's health. 2012;12:31. PubMed PMID: 23031722. Pubmed Central PMCID: PMC3533504. Epub 2012/10/04. eng

22. Mengesha ZB, Worku AG, Feleke SA. Contraceptive adoption in the extended postpartum period is low in Northwest Ethiopia. BMC Pregnancy Childbirth. 2015;15:160. PubMed PMID: 26231369. Pubmed Central PMCID: PMC4522141. Epub 2015/08/02. eng.

23. Bogale B, Wondafrash M, Tilahun T, Girma E. Married women's decision making power on modern contraceptive use in urban and rural southern Ethiopia. BMC Public Health. 2011;11:342. PubMed PMID: 21595897. Pubmed Central PMCID: PMC3114727. Epub 2011/05/21. eng.

24. Yalew SA, Zeleke BM, Teferra AS. Demand for long acting contraceptive methods and associated factors among family planning service users, Northwest Ethiopia: a health facility based cross sectional study. BMC research notes. 2015;8:29. PubMed PMID: 25656470. Pubmed Central PMCID: PMC4340161. Epub 2015/02/07. eng.

25. Gizaw A, Regassa N. Family planning service utilization. J Geogr Regional Plann. 2011:4(6):355-63.

26. Rutaremwa G, Kabagenyi A, Wandera SO, Jhamba T, Akiror E, Nviiri HL. Predictors of modern contraceptive use during the postpartum period among women in Uganda: a population-based cross sectional study. BMC Public Health. 2015;15:262. PubMed PMID: 25885372. Pubmed Central PMCID: PMC4372233. Epub 2015/04/18. eng.

\section{Submit your next manuscript to BioMed Central and we will help you at every step:}

- We accept pre-submission inquiries

- Our selector tool helps you to find the most relevant journal

- We provide round the clock customer support

- Convenient online submission

- Thorough peer review

- Inclusion in PubMed and all major indexing services

- Maximum visibility for your research

Submit your manuscript at www.biomedcentral.com/submit

CBiomed Central 